Journal of Applied Pharmaceutical Science Vol. 5 (05), pp. 028-032, May, 2015

Available online at http://www.japsonline.com

DOI: $10.7324 / \mathrm{JAPS} .2015 .50505$

ISSN 2231-3354 (cc) BY-NC-SA

\title{
Formulation and Evaluation of Ketoconazole Polymeric Films for Topical Application
}

\author{
Mohamed Salama ${ }^{1}$, Mahmoud A. Mahdy ${ }^{2}$, Amina Mohamed ${ }^{3}$, Aref T. Mohamed ${ }^{3}$, Eseldin I. Keleb ${ }^{3}$, Assad A. Omar ${ }^{3}$, \\ Nagib A. Elmarzugi ${ }^{3,4^{*}}$ \\ ${ }^{1}$ Department of Pharmaceutics, Faculty of Pharmacy, Universiti Teknologi MARA, 42300 Bandar Puncak Alam, Selangor, Malaysia. ${ }^{2}$ Faculty of Pharmacy, \\ Zagazig University, Zagazig, Egypt. ${ }^{3}$ Dept. of Industrial Pharmacy, Faculty of Pharmacy, Tripoli University and BioNano Integration Research Group, \\ Biotechnology Research Center, LARST, Tripoli, Libya. ${ }^{4}$ Institute of Bioproduct Development, Universiti Teknologi Malaysia, Johor Bahru 81310, Johor, \\ Malaysia.
}

\section{ARTICLE INFO}

Article history:

Received on: 09/02/2015

Revised on: 10/03/2015

Accepted on: 27/03/2015

Available online: 27/05/2015

Key words

Ketoconazole, Eudragit RL

100, Polymeric film,

Antifungal drugs.

\begin{abstract}
The objective of the current paper was to prepare and evaluate various polymeric films for fungal infection treatment and its impact on volunteer patients. Different Eudragit polymeric films containing Ketoconazole as antifungal drug were prepared by solvent casting technique. The prepared films were tested for their physicomechanical properties as tensile strength, physical endurance, elasticity, water vapor permeation and water loss. The release of ketoconazole from the prepared medicated films was examined. It is involved 20 volunteers suffering from legs fungal infection. Ten of the patients used the films and a follow up study was carried out for 14 days, in comparison with other patients who applied ketoconazole medicated ointment, cream gel and Emulgel. The results revealed that films prepared with Eudragit RL 100 containing glyceryl triacetate produced maximum release of ketoconazole both In vitro and In vivo as compared with other topical dosage forms as ointment, cream, gel and Emulgel. Moreover, the films constitute a simple and convenient method for treatment of various fungal infections. As conclusion, the use of antifungal drugs such as Ketoconazole incorporated in polymeric films, the output results provided promised evidence in the treatment of dermatophytosis.
\end{abstract}

\section{INTRODUCTION}

Medicated polymeric films have found great application in topical therapy, being easily applied and avoid the troubles encountered in oral dosage forms (Mohamed et al., 2013). Fungal infections are so abundant in recent years and require intensive and long time for treatment. Application of medicated substances to the skin is a concept as old as humanity (Crawford \& Hollis, 2007, Deshmane et al., 2009). For treatment of skin infections, wide assortments of topical dosage forms are available (Setty et al., 2010; Namasivayam \& Allen Roy, 2013). It comprises powders, lotions, emulsions, ointments, pastes, aerosols, soaps, plasters, shampoos and other preparations (Weiss et al., 2005). Today, among these preparations,

\section{* Corresponding Author}

Nagib A. Elmarzugi, Research and Innovation Dept., Institute of Bioproduct Development, Universiti Teknologi Malaysia, 81310 UTM Johor Bahru, Johor, Malaysia. Tel: +6075536473, Fax: +6075536464 Email: nagib@ibd.utm.my ointment-like preparations covers about $80 \%$. The application of some ointments to the skin produces systemic actions, which means, that certain degree of absorption occurs. Afterwards, systemic drug administration by the transdermal route was achieved with some cream and ointment preparations for protection and treatment from certain diseases (Mohamed et al., 2011). None of these preparations was satisfactory; the major disadvantage was variable systemic drug absorption due to the absence of specific directions to the area expected to be covered. For such reasons, medicated topical polymeric films are designed to deliver the drug to the skin surface at a controlled rate (Chandak\& Prasad Verma, 2010; Amnuaikit et al., 2005, Tandale \& Wagh, 2011; Zurdo Schroeder et al., 2007). However, many advantages of such solid dosage forms which is including, feasibility of handling, application and manufacturing. Ease of termination of the therapy by removing the system whenever decided and needed. Avoidance of influence G. I. T absorption and the duration of therapeutic effect of these films could be controlled by the constancy of film thickness. 
In case of ointments and creams, the thickness of the applied layer varies with repeated application by patient. Avoidance of drug with small therapeutic index and permits display of only one pharmacological effect show several effects. An alternative route when oral route is not practicable and elimination of nuisance associated with daily repetitive applications of messy ointments and creams, with flexibility of the dose used and has a definite area. Easy to terminate therapy by removing the system. These advantages confirm that drugcontaining polymer films are very promising medicinal preparations, as topical dosage forms and have been approved for drug delivery for topical medication (Auda et al., 2010).

Medicated polymeric films constitute one of the most suitable and easily applicable topical preparations since they produce extra-prolonged effect, easily and conveniently applied (Anisree et al., 2012). Ketoconazole is a broad-spectrum antifungal drug of common use for treatment of various skin infections (Deveda et al., 2010).

The aim of this research article was to prepare and evaluate medicated polymeric films containing ketoconazole in comparison with other topical formulations for treatment of Tinea pedis (athlete's foot or fungal foot infection) infection commonly appearing between the toes of the legs (Rapini et al., 2007).

\section{MATERIALS AND METHODS}

\section{Materials}

Ketoconazole was received as a gift sample from Ranbaxy Laboratories Ltd., Dewas (India). Eudragit RL100 (Rohm Pharma, Germany). Carbopol 940, liquid paraffin, white soft paraffin, propylene glycol, polyethylene glycol400, glyceryl triacetate diethyl phthalate, dimethyl phthalate, (Sigma Aldrich, USA), all other chemicals were analytical grades.

\section{Methods}

Different ketoconazole polymeric films containing $1 \%$ of the drug was prepared using Eudragit RL 100 dissolved in acetonitrile and containing various concentrations of plasticizers. The prepared films were tested for their solid-state characteristics, moisture absorption, mechanical properties, such as tensile strength, folding endurance and release characteristics. The In vitro release of ketoconazole from the prepared films was determined using Franz diffusion cell at $32{ }^{\circ} \mathrm{C}$ and cellulose acetate membrane with a size of $25 \mathrm{~mm}$ in diameter and has 0.45 $\mu \mathrm{m}$ pore size. The In vivo evaluation of the release of ketoconazole from the prepared films was done on healthy volunteers.

\section{Preparation of the polymeric films}

Polymeric films were prepared by dissolving various concentrations of Eudragit RL 100 in methyl alcohol. The concentration of Eudragit ranged from 4 to $10 \%$, the casting technique was used for preparation of the films (Zhang et al., 2007) . The solution mixture was poured on a specifically designed stainless steel spherical assembly consisting of two stainless steel plates of $7.9 \mathrm{~cm}$ internal diameter (area $48.99 \mathrm{~cm}^{2}$ ). The solvent was allowed to evaporate at $37 \pm 0.5{ }^{\circ} \mathrm{C}$ and relative humidity $40 \pm 5 \%$. An inverted funnel was placed over the metallic assembly to prevent rapid evaporation of the solvent. All films were separated from the casting assembly with the help of a sharp blade and then stored in the desiccator till further use. Different plasticizers were employed (Lecomte et al., 2004,Kulkarni et al., 2002).

Water-soluble plasticizers were glycerol, propylene glycol, polyethylene glycol400 and glyceryl triacetate. For waterinsoluble plasticizers both, dimethyl phthalate and diethyl phthalate were used. The concentration of plasticizers used ranged from 1 to $5 \%$. The drug concentration in all films was $1 \%$.

\section{Preparation of Ketoconazole Ointment}

Ketoconazole ointment was prepared by mixing $1 \%$ of the medicament with an oleaginous ointment base consisting of 10 $\%$ liquid paraffin and $90 \%$ soft paraffin.

\section{Preparation of Ketoconazole Gel}

The gel was prepared using $5 \%$ Carbopol 943 and $1 \%$ of ketoconazole in distilled water then the $\mathrm{pH}$ of the gel was adjusted to 5.5 by addition of potassium hydroxide solution.

\section{Preparation of ketoconazole Cream}

The cream was prepared using a vanishing cream base consisting of stearic acid (45 g), potassium hydroxide $(5.0 \mathrm{~g})$, glycerol $(6.0 \mathrm{ml})$ and water to $100 \mathrm{~g}$ (Ugandar\& Deivi, 2013).

\section{Preparation of ketoconazole Emulgel}

An emulsion containing $1 \%$ of ketoconazole emulsified by $5 \%$ of Span 80 in water was mixed with varying amounts of Carbopol 934 gel. Three Emulgel preparations were prepared containing 5, 10 and $15 \mathrm{~g}$ of the Carbopol 934 gel.

\section{Determination of the thickness}

The thickness of prepared films was measured using a micrometer (Mitutoyo, Kanagawa, Japan). Each film was measured for its thickness at 5 different points and the mean values were calculated (Kumar et al., 2010).

Folding endurance measurement test was carried out to check the brittleness of the prepared films. It is conducted by repeated folding of the films in the same place until complete breakdown occurred (Garala et al., 2009). The number of folds required to break the films was determined accordingly.

\section{Moisture uptake study}

The films were put in a desiccator with silica gel for 24 hours and weighed (Wi) using Sartorius AG Göttingen electric balance, Germany. The films were then transferred to another desiccator containing saturated $\mathrm{NaCl}$ solution (relative humidity $75 \%$ ) at $25{ }^{\circ} \mathrm{C}$ until a constant weight was obtained (Kumar\& Prabhushankar\& Sathesh Babu, 2010). After equilibrium was 
attained, the films were taken out and weighed (Wm). Moisture uptake capacity was calculated according to the following equation: (Moisture Uptake Capacity $=(\mathrm{Wm}-\mathrm{Wi} / \mathrm{Wi}) \mathrm{X} 100)$.

\section{Moisture Content Study}

The prepared films were weighed $(\mathrm{Wi})$ and kept in a desiccator containing silica gel at $25{ }^{\circ} \mathrm{C}$ until it showed a constant weight (Wd) [20]. The moisture content was calculated according to the following equation:

$$
\text { Moisture content }(\%)=\mathrm{Wi}-\mathrm{Wd} / \mathrm{Wd} \text { X } 100
$$

$\mathrm{Wd}$ is the weight of the dried polymer film and Ws denotes the weight after swelling

\section{Mechanical Properties Study}

The mechanical properties were evaluated using Chatillon apparatus for force measurement (Greensbro, NC 27409). Rectangular filmstrips of fixed width and length were fixed between the upper and lower jaws. The lower jaw was driven downward with a speed of $1 \mathrm{~mm} / \mathrm{s}$. Load versus displacement curves were recorded until rupture of the film (Ubaidulla et al., 2007,Tekade\& Gattani, 2010). The mechanical properties were determined as follows: $($ Tensile Strength $=$ Breaking force/Area of the film).

Elongation at break $\%=$ Difference in length at breaking point $\mathrm{X}$ 100/Original length.

\section{In vitro Release Studies}

Franz diffusion cell is used to determine the In vitro release of ketoconazole from the tested preparations. The membrane used was cellulose acetate membrane having a pore size of $0.45 \mu$, the release was performed at $32 \pm 0.5^{\circ} \mathrm{C}$ and a pH 5.5 (Azarmi et al., 2007).

\section{In vivo release studies}

This study was carried out in Zagazig University hospital (Zagazig, Egypt). It involved 20 volunteers suffering from legs fungal infection. Ten of the patients used the films and a follow up study was carried out for 14 days, in comparison with other patients (10 patients) who applied ketoconazole medicated ointment, cream gel and Emulgel.

\section{RESULTS AND DISCUSSION}

The modulus of elasticity is an important parameter in determining the degree of hardness, flexibility and stiffness of the polymeric film. This parameter is calculated from the slope of the straight-line portion of the stress strain curve. The value of modulus of elasticity of non-medicated non-plasticized films was found to be 0.382 . This value is relatively high and is indicative of the brittleness and hardness of those films. The inclusion of ketoconazole in the film reduced the modulus of elasticity to a value of 0.309 . This may be attributed to the weakening of the polymer intermolecular binding, allowing the polymer molecules to move more freely resulting in an increase in the flexibility of medicated films. Nevertheless, the medicated films were still exerting some degree of hardness and brittleness. The composition of different prepared films are presented in Table 1.

The addition of plasticizers had a considerable effect on the modulus of elasticity of the medicated Eudragit polymeric films. The results revealed that the addition of water-soluble plasticizers (glyceryl triacetate, glycerol, propylene glycol and polyethylene glycol400) showed a continuous decrease in the value of this parameter as the concentration of the plasticizer added to the film was increased. The effect of water-soluble plasticizers on reducing the modulus of elasticity of plasticized medicated Eudragit RL 100 can be arranged in the following descending order: glyceryl triacetate> glycerol> propylene glycol $>$ polyethylene glycol 400 .

On the other hand, the addition of the water-insoluble plasticizers (diethyl phthalate and dimethyl phthalate) resulted in no considerable changes in the value of modulus of elasticity when higher than $10 \%$ in concentration was added. Dimethyl phthalate was more efficient in reducing the modulus of elasticity than diethyl phthalate, all the previous conditions presented in table 2 .

The mechanical properties of Eudragit RL 100 films under investigation were related to the nature and the concentration of the water-soluble plasticizers used and presented in table 3. On the other hand, Eudragit RL 100 films plasticized with water-insoluble plasticizers was either hard and strong or weak and soft. Moreover, of the six plasticizers investigated, glyceryl triacetate showed the greatest effect on reducing the modulus of elasticity, whereas diethyl phthalate had the lowest effect.

Concerning the tensile strength of the medicated polymeric films as calculated from the stress strain curve, it was noticed that the addition of plasticizers resulted in a reduction of the tensile strength. The tensile strength of non-medicated nonplasticized Eudragit RL100, films was found to be $96.12 \mathrm{~kg} / \mathrm{cm}^{2}$, whereas the inclusion of ketoconazole in the films reduced the tensile strength to $80.07 \mathrm{~kg} / \mathrm{cm}^{2}$.

The study showed that the addition of increasing concentrations of the plasticizers under investigation from 10 to 20 $\%$ (W/W of polymer) resulted in increasing the percent of elongation to varying extents. The medicated Eudragit RL 100 films plasticized with water-soluble plasticizers showed a considerable increase in the percent of elongation when compared with the films plasticized with water-insoluble plasticizers.

The results indicate that as the concentration of the polymer increased there was an increase in the thickness of the film. Moisture absorption is more in films having high amount of the hydrophilic polymer while low in films having high amount of the hydrophobic polymer; Eudragit RL100. Moisture loss was highest in films having the less concentration of the hydrophobic polymer Eudragit RL100 which offered minimum hindrance for the transfer of moisture, while lowest in films having high amount of the hydrophobic polymer Eudragit RL 100. The presence of plasticizer imparts flexibility to the polymer. This flexibility of the films facilitates their removal from the casting moulds and makes their application on the skin easier. 
Table 1: Composition of the Prepared Films.

\begin{tabular}{|c|c|c|c|c|c|}
\hline Formula I & Formula II & Formula III & Formula IV & Formula V & Formula VI \\
\hline Ketoconazole $100 \mathrm{mg}$ & Ketoconazole $100 \mathrm{mg}$ & Ketoconazole $100 \mathrm{mg}$ & Ketoconazole $100 \mathrm{mg}$ & Ketoconazole $100 \mathrm{mg}$ & Ketoconazole $100 \mathrm{mg}$ \\
\hline Eudragit RL 100400 mg & $\begin{array}{l}\text { Eudragit RL } 100500 \\
\text { mg }\end{array}$ & Eudragit RL $100750 \mathrm{mg}$ & $\begin{array}{l}\text { Eudragit RL } 1001000 \\
\text { mg }\end{array}$ & $\begin{array}{l}\text { Eudragit RL } 1001250 \\
\text { mg }\end{array}$ & $\begin{array}{l}\text { Eudragit RL } 1001500 \\
\text { mg }\end{array}$ \\
\hline Glyceryl triacetate & Glyceryl triacetate 0.75 & Glyceryl triacetate & Glyceryl triacetate & Glyceryl triacetate & Glyceryl triacetate 1.75 \\
\hline $0.5 \mathrm{ml}$ & $\mathrm{ml}$ & $1.0 \mathrm{ml}$ & $1.25 \mathrm{ml}$ & $1.50 \mathrm{ml}$ & $\mathrm{ml}$ \\
\hline Acetonitrile to $10 \mathrm{ml}$ & Acetonitrile to $10 \mathrm{ml}$ & Acetonitrile to $10 \mathrm{ml}$ & Acetonitrile to $10 \mathrm{ml}$ & Acetonitrile to $10 \mathrm{ml}$ & Acetonitrile to $10 \mathrm{ml}$ \\
\hline
\end{tabular}

Table 2: Effect of Different Plasticizers (10\%) on the Modulus of Elasticity of Eudragit RL100 (10\%) Polymeric Films.

\begin{tabular}{|c|c|c|c|}
\hline Plasticizer & Tensile Strength (MP) & Elastic Modulus (MPa) & Appearance of Film \\
\hline \multicolumn{4}{|c|}{ Water-soluble plasticizers } \\
\hline Glyceryl triacetate & $3.7 \pm 1.2$ & $394 \pm 21.1$ & good-elastic \\
\hline Glycerol & $3.4 \pm 1.5$ & $290 \pm 15.1$ & semi-elastic \\
\hline Propylene Glycol & $2.54 \pm 0.06$ & $256 \pm 19.9$ & Brittle \\
\hline PEG 400 & $2.50 \pm 0.26$ & $235 \pm 23.2$ & Soft \\
\hline \multicolumn{4}{|c|}{ Water-insoluble plasticizers } \\
\hline Dimethyl phthalate & $2.44 \pm 0.05$ & $305 \pm 15$ & hard and brittle \\
\hline Diethyl phthalate & $2.34 \pm 0.6$ & $268 \pm 25$ & Soft and brittle \\
\hline
\end{tabular}

Table 3: Physico-mechanical Properties of the Prepared Films.

\begin{tabular}{|c|c|c|c|c|c|}
\hline Formula Number & Thickness (nm) & Tensile Strength (\%) & Folding Endurance (Folds) & Moisture Absorption (\%) & Water Loss (\%) \\
\hline $\mathrm{I}$ & $285 \pm 1.12$ & $75 \pm 1.11$ & $90 \pm 0.50$ & $10 \pm 1.05$ & $7 \pm 1.20$ \\
\hline II & $295 \pm 1.05$ & $69 \pm 0.80$ & $88 \pm 1.11$ & $12 \pm 1.11$ & $7.5 \pm 1.05$ \\
\hline III & $310 \pm 1.12$ & $67 \pm 0.50$ & $88 \pm 1.05$ & $13 \pm 1.12$ & $8 \pm 0.075$ \\
\hline IV & $312 \pm 1.11$ & $66 \pm 1.11$ & $86 \pm 0.85$ & $14 \pm 1.06$ & $8.2 \pm 1.11$ \\
\hline $\mathrm{V}$ & $315 \pm 1.05$ & $65 \pm 1.05$ & $84 \pm 1.11$ & $15 \pm 0.95$ & $8.5 \pm 1.11$ \\
\hline VI & $322 \pm 1.11$ & $65 \pm 1.12$ & $82 \pm 1.05$ & $15 \pm 1.11$ & $9 \pm 1.20$ \\
\hline
\end{tabular}

A good relationship between the flexibility of the polymeric films and their efficacy was demonstrated. The folding endurance test is important to check the ability of the sample to withstand folding. This also gives an indication of brittleness. The folding endurance was found between 83 and 90 folds, which is considered satisfactory and reveals good film property. The in vitro release of ketoconazole from the prepared polymeric films and from ketoconazole ointment and gel, which is illustrated in Figure 1.

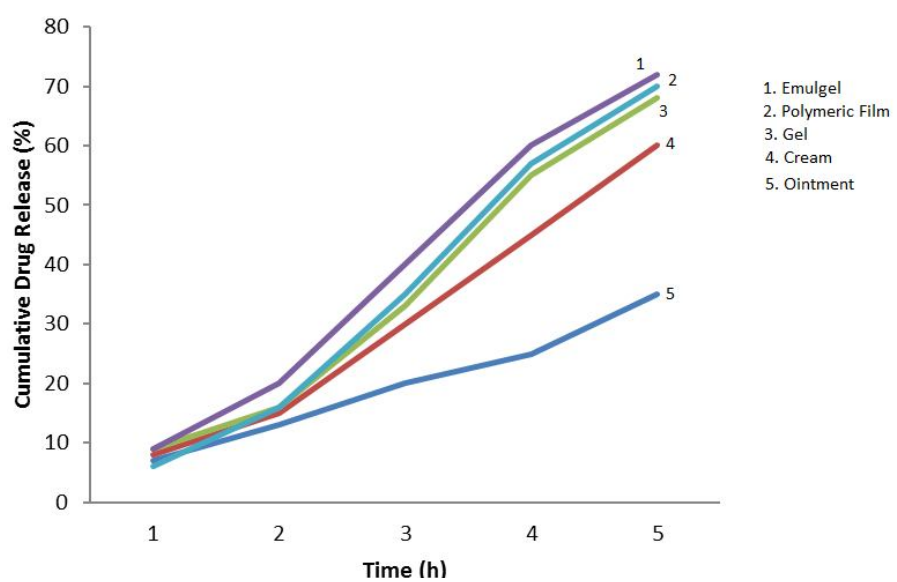

Fig. 1: The In vitro cumulative drug release from the different topical preparations against time as tested by Franz diffusion cell.

It shows obviously, that the amount of drug released for a period of 5 hours was higher from gel than the polymeric films, being $67 \%$ of the contained amount in comparison with that released from the film $54 \%$. ketoconazole ointment was the lowest in this concern releasing only $46 \%$ of the contained drug , this may be due to the hydrophobic nature of the drug and its solubility in paraffin base do not facilitate its release to the aqueous medium. In-vivo release of Ketoconazole from the tested topical preparations; six Eudragit films of different medicated polymeric ratios were tested for the release of ketoconazole from them film in comparison with gels and ointments. The results revealed that the formulation of ketoconazole in dermal polymeric films for topical application might present a novel drug delivery system as compared with other conventional dermatologic preparations versus creams, gels, ointments and Emulgel. Curing was observed beneath the films (disappearance of the pale whitish coloured skin) within 12 hours. Complete relief of Tinea pedis infections associated with itching occurred within 2 weeks. The In vitro released of ketoconazole from the prepared polymeric films and from ketoconazole ointment and gel. It is obvious that the amount of drug released for a period of 5 hours was higher from Emulgel than the polymeric films, being $72 \%$ of the contained amount when compared with the amount that released from the film; $70 \%$.

ketoconazole ointment was the lowest in this concern releasing only $35 \%$ of the contained drug, this may be due to the hydrophobic nature of the drug and its solubility in paraffin base do not facilitate its release to the aqueous medium. The current obtained results provided; that the medicated polymeric films showed good physical and mechanical properties. The In vitro release from the different topical preparations illustrated that the amount released ranged from 35 to $72 \%$ of the incorporated amount of drug. Moreover, there was no significant variation for all the tested preparations In vitro, while the In vivo studies which actual image from a volunteer in Figure 2 presented and were surprisingly higher for the medicated films over other 
preparations. This indicates the effectiveness of applied polymeric films over other tested topical preparations.

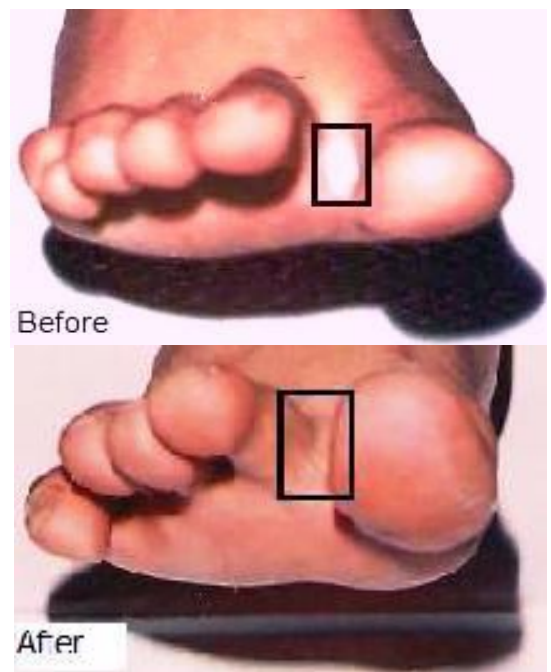

Fig. 2: In vivo drug release from medicated polymeric films of ketoconazole on human volunteers.

\section{CONCLUSION}

The in vitro studies were conducted to evaluate the effectiveness of the medicated films in treating Tinea pedis. Films prepared with Eudragit RL100 containing glyceryl triacetate as a water-soluble plasticizer proved to be more elastic and flexible, being easily removed from the casting molds and even more easy when applied on the human skin. Furthermore, medicated polymeric films proved to be more effective than other topical preparations in treatment of fungal infection, since complete healing occurred within 5 days of treatment. Moreover, the polymeric films are more convenient in application being less adhesive and produce a more prolonged effect.

\section{REFERENCES}

Mohamed MS, Eid AM, Elgadir M, Mahdy MA. Preparation and release characteristics of Itracinazole poymeric films for topical application. International Journal of Pharmacy \& Pharmaceutical Sciences, 2013; 5:167-170.

Crawford F, Hollis S. Topical treatments for fungal infections of the skin and nails of the foot. Cochrane Database Syst Rev, 2007;18;(3): CD001434.

Deshmane SV, Channawar MA, Chandewar AV, Joshi UM, Biyani KR. Chitosan based sustained release mucoadhesive buccal patches containing verapamil HCl. Int J Pharm, 2009;1:216-229.

Setty C, Babubahi S, Pathan I. Development of Veldecoxib topical gels: Effect of formulation variables on the release of valdecoxib. Int J Pharm Pharma Sci, 2010;2:70-73.

Namasivayam SKR, Allen Roy E. Anti biofilm effect of medicinal plant extracts against clinical isolate of biofilm of Escherichia coli. International Journal of Pharmacy and Pharmaceutical Research, $2013 ; 5: 486-489$.

Weiss J, Scherze I, Muschiolik G. Polysaccharide gel with multiple emulsion. Food Hydrocolloids, 2005; 19:605-615.

Mohamed MI, Haider M, Muaadh A, Ali M. Buccal Mucoadhesive Films Containing Antihypertensive Drug: In vitro/In vivo
Evaluation. Journal of Chemical and Pharmaceutical Research, 2011; 3:665-686.

Chandak AR, Prasad Verma PR. Eudragit-based transdermal delivery system of pentazocine: Physico-chemical, In vitro and In vivo evaluations. Pharmaceutical Development and Technology, 2010;15:296304.

Amnuaikit C, Ikeuchi I, Ogawara K-i, Higaki K, Kimura T. Skin permeation of propranolol from polymeric film containing terpene enhancers for transdermal use. International Journal of Pharmaceutics $2005 ; 289: 167-178$.

Tandale YN, Wagh VD. Formulation and evaluation of dorzolamide hydrochloride polymeric film. Int J Pharm Tech Res, 2011; 3:1817-1824.

Zurdo Schroeder I, Franke P, Schaefer UF, Lehr C-M. Development and characterization of film forming polymeric solutions for skin drug delivery. European Journal of Pharmaceutics and Biopharmaceutics, 2007; 65:111-121.

Auda SH, Ahmed MM, El-Rasoul SA, Saleh K. Formulation and physicochemical characterization of piroxicam containing polymer films. Bull. Pharm. Sci., 2010; 33:33-42.

Anisree G, Ramasamy C, John WI. Fabrication and evaluation of Domperidone transdermal films. International Journal of Pharmacy \& Pharmaceutical Sciences, 2012; 289:167-178.

Deveda P, Jain A, Vyas N, Khambete H, Jain S. Gellified emulsion for sustain delivery of itraconazole for topical fungal diseases. International Journal of Pharmacy and Pharmaceutical Sciences, 2010; 2:104-111

Rapini RP, Bolognia JL, Jorizzo JL. 2007. Dermatology: 2Volume Set. St. Louis: Mosby.

Zhang X, Wang Y, Wang J, Wang Y, Li S. Effect of pore former on the properties of casted film prepared from blends of Eudragit NE 30 D and Eudragit L 30 D-55. Chemical and Pharmaceutical Bulletin, 2007; 55:1261-1263.

Lecomte F, Siepmann J, Walther M, MacRae R, Bodmeier R. Polymer blends used for the aqueous coating of solid dosage forms: importance of the type of plasticizer. Journal of Controlled Release, 2004; 99:1-13.

Kulkarni R, Mutalik S, Hiremath D. Effect of plasticizers on the permeability and mechanical properties of Eudragit films fortransdermal application. Indian Journal of Pharmaceutical Sciences, 2002; 64:28-31.

Ugandar R, Deivi KS. Formulation and evaluation of natural palm oil based vanishing cream. International Journal of Pharmaceutical Sciences and Research, 2013; 4:3375-3380.

Kumar M, Prabhushankar G, Sathesh Babu P. Formulation and In-Vitro Evaluation of Periodontal Films Containing Metronidazole. International Journal of PharmTech Research, 2010; 2(4): 2188-2193.

Garala KC, Shinde AJ, Shah PH. Formulation and in-vitro characterization of monolithic matrix transdermal systems using HPMC/Eudragit S 100 polymer blends. International Journal of Pharmacy and Pharmaceutical Sciences, 2009; 1:108-120.

Ubaidulla U, Reddy MVS, Ruckmani K, Ahmad FJ, Khar RK. Transdermal therapeutic system of carvedilol: Effect of hydrophilic and hydrophobic matrix on In vitro and In vivo characteristics. AAPS PharmSciTech, 2007; 8:E13-E20.

Tekade A, Gattani S. Investigation on Physical-Mechanical Properties of Natural Polymer Films. International Journal of PharmTech Research , 2010;2(01): 106-112.

Azarmi S, Roa W, Löbenberg R. Current perspectives in dissolution testing of conventional and novel dosage forms. International Journal of Pharmaceutics, 2007; 328:12-21.

How to cite this article:

Mohamed Salama, Mahmoud A. Mahdy, Amina Mohamed, Aref T. Mohamed, Eseldin I. Keleb, Assad A. Omar, Nagib A. Elmarzugi., Formulation and Evaluation of Ketoconazole Polymeric Films for Topical Application. J App Pharm Sci, 2015; 5 (05): 028-032. 